\title{
Calculation of energy lost by radiation and convection during laser welding of TA6V titanium alloy
}

\author{
Soumaya Lemkeddem ${ }^{1,2} \cdot$ Fethi Khelfaoui $^{1} \cdot$ Oumelkheir Babahani ${ }^{1}$
}

Received: 5 March 2018 / Accepted: 2 July 2018 / Published online: 7 July 2018

(C) The Author(s) 2018

\begin{abstract}
Laser welding is being used more frequently in industrial processes because of its advantages; therefore, energy loss in welding is an important issue during planning and operation. We calculated the energy losses expected during the laser welding of TA6V titanium alloy. We used the heat equation to describe the energy distribution of solid and liquid TA6V. The solid-to-liquid phase change was taken into account by comparing the accumulated energies and enthalpy of fusion. A numerical model was used to calculate the energy lost by convection and radiation. Finite difference calculations were performed using a FORTRAN-based computer program to solve the heat equation. The numerical results suggested that the appropriate laser welding velocity and power were in good agreement with the experimental data published elsewhere in the literature. The results showed the importance of the influence of the energy lost by radiation and convection in the welding area on welding energies and temperatures.
\end{abstract}

Keywords Laser welding · Heat equation · Enthalpy of fusion · Convection · Thermal radiation · Titanium alloy

\section{List of symbols}

$C_{\mathrm{p}} \quad$ Specific heat $\left(\mathrm{J} \mathrm{kg}^{-1} \mathrm{~K}^{-1}\right)$

$C_{\mathrm{PL}} \quad$ Specific heat of solid phase $\left(\mathrm{J} \mathrm{kg}^{-1} \mathrm{~K}^{-1}\right)$

$C_{\mathrm{PS}} \quad$ Specific heat of liquid phase $\left(\mathrm{J} \mathrm{kg}^{-1} \mathrm{~K}^{-1}\right)$

$h \quad$ Heat transfer coefficient $\left(\mathrm{W} \mathrm{m}^{-2} \mathrm{~K}^{-1}\right)$

$L_{x}, L_{y} \quad$ Geometry dimensions (m)

$P \quad$ Laser power $(\mathrm{W})$

$Q \quad$ Power density $\left(\mathrm{W} \mathrm{m}^{-3}\right)$

$Q_{0} \quad$ Power density at the center of the beam $\left(\mathrm{W} \mathrm{m}^{-3}\right)$

$Q_{\mathrm{W}} \quad$ Power density of lost energy $\left(\mathrm{W} \mathrm{m}^{-3}\right)$

$R \quad$ Laser beam radius $(\mathrm{m})$

$t \quad$ Time (s)

$T \quad$ Temperature (K)

$T_{0} \quad$ Ambient temperature (K)

$T_{\beta} \quad \beta$-Transus Temperature (K)

$T_{\mathrm{F}} \quad$ Meting point $(\mathrm{K})$

Soumaya Lemkeddem

slemkeddem@gmail.com

1 Lab. Rayonnement et Plasmas et Physique des Surfaces, Fac. des Mathématiques et des Sciences de la Matière, Univ. Ouargla, 30000 Ouargla, Algeria

2 Fac. des Sciences Appliquées, Univ. Ouargla, 30000 Ouargla, Algeria
$V \quad$ Welding velocity $(\mathrm{m} / \mathrm{s})$

$W_{\text {ray }} \quad$ Energy lost by radiation (J)

$W_{\text {conv }}$ Energy lost by convection $(\mathrm{J})$

$x, y \quad$ Cartesian coordinates $(\mathrm{m})$

$d \varphi \quad$ Accumulated energy (J)

$d s \quad$ surface element $\left(\mathrm{m}^{2}\right)$

$\varepsilon \quad$ Emissivity

$\varepsilon_{\mathrm{S}} \quad$ Emissivity of solid phase

$\varepsilon_{\mathrm{L}} \quad$ Emissivity of liquid phase

$\varepsilon_{\mathrm{SL}} \quad$ Emissivity of solid-liquid phase change

$\lambda$ Thermal conductivity $\left(\mathrm{W} \mathrm{m}^{-1} \mathrm{~K}^{-1}\right)$

$\lambda_{\mathrm{S}} \quad$ Thermal conductivity of solid phase $\left(\mathrm{W} \mathrm{m}{ }^{-1} \mathrm{~K}^{-1}\right)$

$\lambda_{\mathrm{L}} \quad$ Thermal conductivity of liquid phase $\left(\mathrm{W} \mathrm{m} \mathrm{m}^{-1}\right.$ $\mathrm{K}^{-1}$ )

$\lambda_{\mathrm{SL}} \quad$ Thermal conductivity of solid-liquid phase change (W m ${ }^{-1} \mathrm{~K}^{-1}$ )

$\rho \quad$ Density $\left(\mathrm{kg} \mathrm{m}^{-3}\right)$

$\rho_{\mathrm{S}} \quad$ Density of solid phase $\left(\mathrm{kg} \mathrm{m}^{-3}\right)$

$\rho_{\mathrm{L}} \quad$ Density of liquid phase $\left(\mathrm{kg} \mathrm{m}^{-3}\right)$

$\sigma \quad$ Stefan-Boltzmann constant $\left(\mathrm{W} \mathrm{m}^{-2} \mathrm{~K}^{-4}\right.$ )

$\alpha_{\mathrm{k}} \quad$ Parameters for numerical expressions

$\gamma_{\mathrm{k}} \quad$ Parameters for numerical expressions

$\beta_{\mathrm{k}} \quad$ Parameters for numerical expressions 


\section{Introduction}

TA6V is the most widely used titanium alloy because it shows excellent mechanical properties at high temperatures $[1,2]$. TA6V is commonly used in industrial applications such as aeronautics and aerospace equipment [3] and in biomechanical applications such as implants and prostheses $[4,5]$. Although TA6V can be assembled from a variety of welding processes, laser welding presents a practical option owing to its high heat input and flexibility [6], which lead to small heat-affected zones and high welding velocities. Several physical phenomena can occur during laser welding, causing part of the energy to be lost. Such energy losses can reduce the efficiency of laser welding.

It is important to develop numerical techniques in order to simulate the thermal consequences of laser welding because experimental investigations can be difficult, impractical, time-consuming, and prohibitively expensive. Several works have focused on numerical analyses of welding [7]; the obtained numerical results can be used to optimize welding parameters and to explain the physics of some phenomena that occur during welding. Thus, numerical modeling is a powerful tool for understanding welding conditions and parameters.

Davis et al. [8] used numerical model to study laser welding of different metals. They found correlations between various welding parameters without considering energy losses. Abderrazak et al. [9] used also numerical model to analyze the formation of pools of molten metal during laser welding without considering energy losses.

Bannour et al. [10] have studied the temperature dependence of physical properties during welding, and they have considered convection losses. Several authors have shown that energy dissipates on surface by convection and radiation [11, 12]. Belhadj et al. [13] considered surface convection losses; they assumed the losses by radiation are on surfaces irradiated with the laser beams. They develop a model for simulating thermal history during laser welding. Abderrazak et al. [14] estimated both thermal convection and radiation phenomena in welding areas to develop a thermal model for predicting the different parameters expected during the welding of magnesium alloys. We point out that some researchers prefer using a single heat loss equation in which they combine the effects of radiation and convection into a single heat transfer coefficient [15-17].

In our knowledge, there is a paucity of research on calculating of the energy rate due to convection and radiation during welds; therefore, the present paper aims to quantify the amount of energy lost by convection and by radiation during the $\mathrm{CO}_{2}$ laser welding of thin plates of TA6V.
Mathematical model and numerical method

The laser welding of a thin plate results in uniform properties in depth. Therefore, the welding temperatures were assumed to be identical at all penetration depths under the welding conditions used in this study. For simplicity, we assumed that energy lost though the surface by radiation and by convection could be treated by two-dimensional model without loss of generality.

\section{Heat source model}

The power density, $Q$, produced by a focused beam is very intense, thereby allowing the melting of metal. A keyhole will be formed to transmit the energy to the metal. During welding laser, the keyhole was maintained directly under the laser beam. For laser velocity $V$ and laser beam radius $R$, a Gaussian surface distribution was used and it is expressed as follows:

$Q_{(r, t)}= \begin{cases}Q_{0} \exp \left(\frac{-r^{2}(t)}{R^{2}}\right) & r \leq 2 R \\ 0 & r>2 R\end{cases}$

with: $r^{2}(t)=x^{2}+(y-V t)^{2}$.

Note that $Q_{0}$ is chosen to have the total laser power $P$. The power density is $Q(R, t)=\exp (-1) Q_{0}=0.37 Q_{0}$ for $r=R$, and it is $Q(2 R, t)=\exp (-4) Q_{0}=0.02 Q_{0}$ for $r=2 R$; the energy distribution is practically around $R$.

\section{Assumptions and governing equations}

The geometrical configuration of the problem and the corresponding Cartesian coordinate system are shown in Fig. 1. The mathematical formulation of the model was based on the following assumptions:

1. The initial temperature of the work piece was $T_{0}=300 \mathrm{~K}$;

2. The laser beam was moved at a constant velocity, $V$;

3. A perfect contact joint was welded between two identical parts;

4. The thermal analysis was only performed on half the assembly;

5. Energy was assumed to be lost only by radiation and by convection.

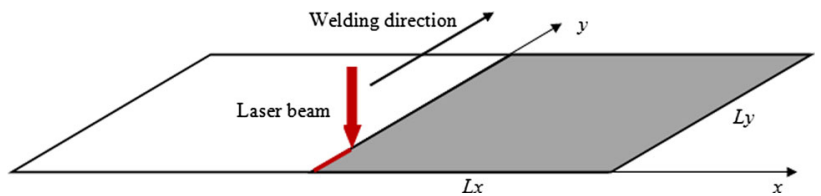

Fig. 1 Presentation of the problem 
The governing equation for energy is the heat equation. It is expressed as follows:

$\rho C_{\mathrm{P}}\left[\frac{\partial T}{\partial t}\right]=\lambda \operatorname{div}(\operatorname{grad} T)+Q-Q_{\mathrm{W}}$

An important temperature gradient was produced from the beginning to the end of laser welding, so the TA6V could transit from solid to liquid. Since the characteristics of metals are temperature dependent, we assumed that each phase would show different average thermal conductivity, density, specific heat, and emissivity.

Heat distribution in the solid phase obeys the following equation:

$$
\begin{aligned}
\rho_{\mathrm{s}} C_{\mathrm{ps}} \frac{\partial T_{(x, y, t)}}{\partial t}= & \lambda_{\mathrm{s}} \nabla^{2} T_{(x, y, t)}+Q_{(x, y, t)}-\sigma \varepsilon_{\mathrm{S}}\left(T_{(x, y, t)}^{4}-T_{0}^{4}\right) \\
& -h\left(T_{(x, y, t)}-T_{0}\right)
\end{aligned}
$$

Heat distribution in the liquid phase obeys the following equation:

$$
\begin{aligned}
\rho_{\mathrm{L}} C_{\mathrm{pL}} \frac{\partial T_{(x, y, t)}}{\partial t}= & \lambda_{L} \nabla^{2} T_{(x, y, t)}+Q_{(x, y, t)}-\sigma \varepsilon_{L}\left(T_{(x, y, t)}^{4}-T_{0}^{4}\right) \\
& -h\left(T_{(x, y, t)}-T_{0}\right)
\end{aligned}
$$

To account for the transition between the solid phase and liquid phase, we computed the amount of energy, $d \varphi$, accumulated in an elementary volume [18] and we compared with the enthalpy of fusion. We assumed that the welding temperature varied linearly during the phase transition.

$$
\begin{aligned}
\mathrm{d} \varphi= & \left(\lambda_{\mathrm{SL}} \operatorname{grad} T_{(x, y, t)} \cdot \vec{n} . \mathrm{d} s-\sigma \varepsilon_{\mathrm{SL}} \mathrm{d} s\left(T_{(x, y, t)}^{4}-T_{0}^{4}\right)\right. \\
& \left.-h \mathrm{~d} s\left(T_{(x, y, t)}-T_{0}\right)\right) \mathrm{d} t+Q(x, y, t)
\end{aligned}
$$

\section{Numerical model and boundary condition}

For the numerical model, the finite difference method (FDM) was used to simulate thermal behavior. The principal idea is to replace the partial differential equations by an equivalent and approximate set of algebraic equations. Equations 3, 4, and 5 are discretized in space and time; they can be written as:

$$
\begin{aligned}
& \alpha_{1} T_{(i-1, j)}^{n+1}-\alpha_{2} T_{(i, j)}^{n+1}+\alpha_{1} T_{(i+1, j)}^{n+1} \\
& \quad=T_{(i, j)}^{n+}-\alpha_{3}\left(T_{i, j-1)}^{n+1}+T_{(i, j+1)}^{n+1}\right)-\alpha_{4} Q_{(i, j)}-\beta_{1} \\
& \alpha_{5} T_{(i-1, j)}^{n+1}-\alpha_{6} T_{(i, j)}^{n+1}+\alpha_{5} T_{(i+1, j)}^{n+1} \\
& \quad=T_{(i, j)}^{n}-\alpha_{7}\left(T_{i, j-1)}^{n+1}+T_{(i, j+1)}^{n+1}\right)-\alpha_{8} Q_{(i, j)}-\beta_{2} \\
& \mathrm{~d} \varphi_{(i, j)}=2 \gamma_{1} T_{(i+1, j))}^{n+1}-\gamma_{2} T_{(i-1, j)}^{n+1}+2 \gamma_{1} T_{(i, j+1)}^{n+1}+\gamma_{3}
\end{aligned}
$$

where $i$ and $j$ are space steps for, respectively, $x$ - and $y$-axis (for mesh indexes), $n$ is the time step, and parameters $\alpha_{k}, \gamma_{k}$, and $\beta_{k}$ are constants and parameters related to physical properties and numerical values of the discretized system.

We developed a FORTRAN-based computer program. The Gauss-Seidel iterative algorithm was used to solve the equations. The time step and mesh construction depended on the laser beam dimension and the welding velocity; a dense mesh was used near the weld bead.

Boundary conditions are as follows (shown in Fig. 2):

1. Along the axe $y=0:(\partial T / \partial y)_{y=0}=0$

2. On $y=L_{y}:(\partial T / \partial y)_{y=L_{y}}=0$

3. On $x=L_{x} ; T\left(L_{x}, y\right)=T_{0}$

4. Along the axe of symmetry $(x=0)$, we assumed a zero heat flux on the contact between two parts to be assembled.

The general scheme of calculation, for a time step $n$, is as follows:
Fig. 2 Geometry, mesh, and boundary conditions

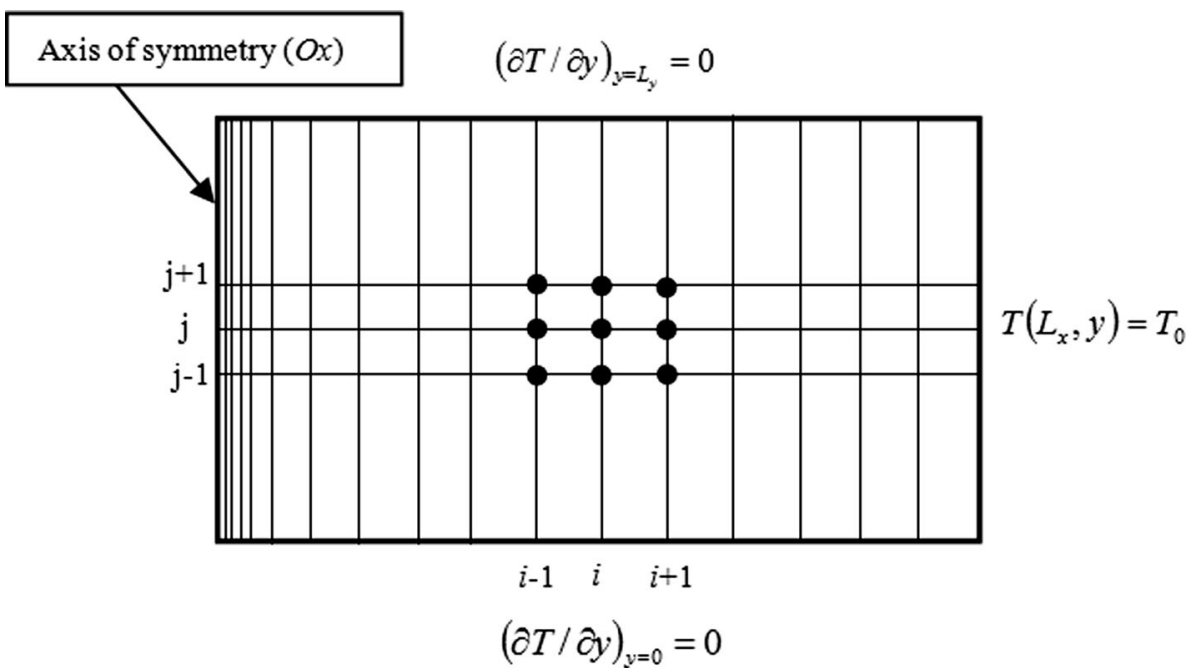


- For a $j$ value:

(a) Identification of nodes phase (solid, liquid, phase transition) of meshes for all values $i$,

(b) Calculation of elements of matrix $A$ and $B$ for values $i$,

(c) Calculation of the temperature $T^{n}(i, j)$, at time $n$, by Gauss-Seidel iterative method,

(d) Repeat calculation (a)-(c) for other value $j=j+1$.

- Verification of convergence and stability of solution $T^{n}(i, j)$ for the same time step $n$ for all $i$ and $j$ values,

- Calculation for the next step time $n+1$ if the convergence is verified.

With this scheme, the calculation, for the proposed time of welding and for the dimension of the two parts and laser beam power, will be stable and will not affect the generality of result.

\section{Material properties}

Unalloyed titanium consists of two allotropes. At ambient temperature, titanium shows the hexagonal-close-packed (hcp) $(\alpha)$ crystal structure. Near the $\beta$-transus temperature, $T_{\beta}=1155 \mathrm{~K}$ [19], titanium allotropically transforms into the body-centered-cubic (bcc) $(\beta$ ) phase. Therefore, titanium alloys are classified according to their favored structure (usually $\alpha, \beta$, or $\alpha-\beta$ ) under ambient conditions.

TA6V, the most commonly used of $\alpha-\beta$ titanium alloy, is composed of $6 \%$ of aluminum, $4 \%$ of vanadium, and residual elements. The $\beta$-transus temperature range of TA6V is $T_{\beta} \approx 1253-1268 \mathrm{~K}$ [20], which is important for determining the TA6V structure. In this work, TA6V melted in the range 1913-1933 K. An average temperature of $T_{\mathrm{f}}=1923 \mathrm{~K}$ was used as melting point, as previously has been used by many authors [2, 21, 22].

Titanium exhibits some excellent characteristics for fusion welding [23]. Since an important temperature gradient was produced during laser welding, the physical characteristics of the material must be temperature dependent. Boiniveau et al. [3] investigated the effect of welding temperature on the physical properties of solid and liquid TA6V, which are published elsewhere in the literature $[2,21]$. Table 1 presents physical properties of TA6V;

Table 1 Physical properties of TA6V titanium alloy

\begin{tabular}{llll}
\hline & Solid & Solid/liquid & Liquid \\
\hline$\rho\left(\mathrm{kg} \mathrm{m}^{-3}\right)$ & 4300 & 4100 & 3850 \\
$C_{P}\left(\mathrm{~J} \mathrm{~kg}^{-1} \mathrm{~K}^{-1}\right)$ & 610 & 770 & 830 \\
$\lambda\left(\mathrm{W} \mathrm{m}^{-1} \mathrm{~K}^{-1}\right)$ & 15 & 27.5 & 35 \\
$\varepsilon$ & 0.25 & 0.40 & 0.40 \\
\hline
\end{tabular}

we exploited these values and others in this work. The heat transfer coefficient, $h=50 \mathrm{Wm}^{-2} \mathrm{~K}^{-1}$ [2], was temperature independent. The used absorption coefficient is $\eta=0.34[2]$.

\section{Results and discussion}

Geometry dimensions were $L_{x}=0.050 \mathrm{~m}$ in length and $L_{y}=0.006 \mathrm{~m}$ in width. With an average velocity of $V=0.060 \mathrm{~m} / \mathrm{s}$, the time required to weld a distance of $0.006 \mathrm{~m}$ is $0.1 \mathrm{~s}$. Laser beam radius was $R=0.30 \mathrm{~mm}$. Temperature distribution was calculated as a function of welding time and position during the laser welding. To get a stable calculation, the maximum value of time step is $\Delta t=4 \times 10^{-5} \mathrm{~s}$ with an irregular mesh sizes $(\Delta x=$ variable and $\Delta y=5 \cdot 10^{-5} \mathrm{~m}$ ). If we want to increase the accuracy of the calculations, we must check $\Delta t \leq 10^{-5} \mathrm{~s}$ under the welding conditions used in this study. The mesh sizes vary, and the time step size is usually determined by the smallest mesh sizes $\left(\Delta x=5 \times 10^{-5} \mathrm{~m}\right.$ and $\left.\Delta y=5 \cdot 10^{-5} \mathrm{~m}\right)$. For a better presentation of the results and their analyses, we will present the lengths $x, y$ and $R$ in $\mathrm{mm}$ in the rest of this section.

Figure 3 illustrates temperature evolution for $P=2500 \mathrm{~W}$ of laser power and different welding velocities at the point $(x=0 \mathrm{~mm}, y=3.0 \mathrm{~mm})$. A similar trend of temperature evolution was observed for different welding velocities. It is clearly seen that the peak welding temperature was increased by decreasing the welding velocity. It can be noted that for a welding velocity $V$ $\leq 0.060 \mathrm{~m} / \mathrm{s}$ the temperature can reach the melting point

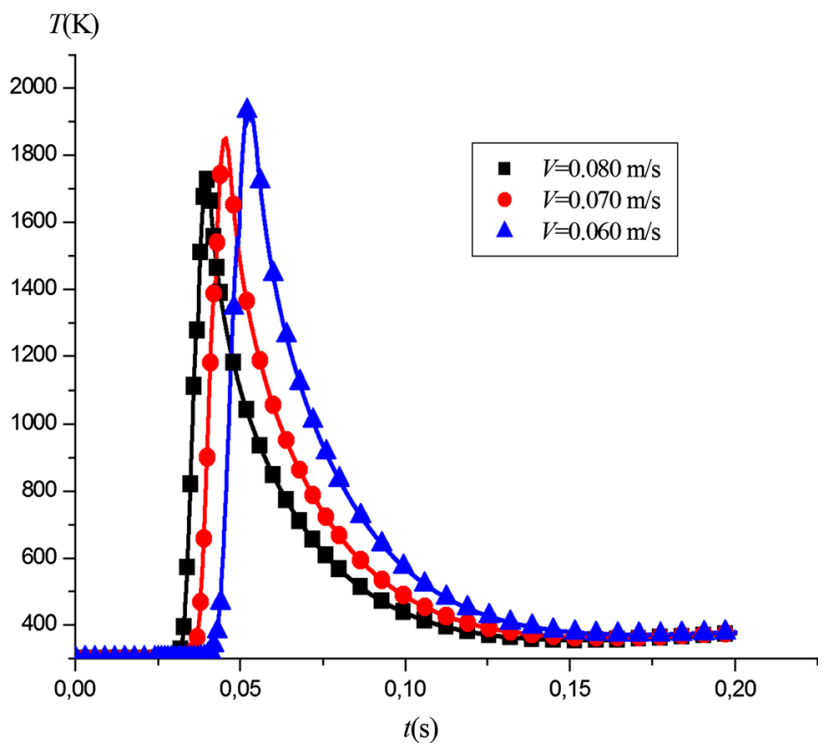

Fig. 3 Temperature evolution for $P=2500 \mathrm{~W}$ of laser power and different welding velocities at $(x=0 \mathrm{~mm}, y=2.0 \mathrm{~mm})$ 
Table 2 Appropriate welding conditions

\begin{tabular}{llll}
\hline $\begin{array}{l}\text { Laser } \\
\text { power } \\
(\mathrm{W})\end{array}$ & $\begin{array}{l}\text { Our } \\
\text { numerical } \\
\text { results } \\
(\mathrm{m} / \mathrm{s})\end{array}$ & $\begin{array}{l}\text { Experimental } \\
\text { results of Ahn et al. } \\
{[20]} \\
(\mathrm{m} / \mathrm{s})\end{array}$ & $\begin{array}{l}\text { Experimental results } \\
\text { of Caiazzo et al. [24] } \\
(\mathrm{m} / \mathrm{s})\end{array}$ \\
\hline$P=2000$ & $V \leq 0.040$ & $V=0.030-0.070$ & $V=0.024$ \\
$P=2500$ & $V \leq 0.065$ & $V=0.030-0.080$ & $V=0.036$ \\
\hline
\end{tabular}

on the weld bead. With well-studied conditions, we have looked for the appropriate welding conditions. These results were in good agreement with the experimental results of Caiazzo et al. [24] and Ahn et al. [20]. The results are presented in Table 2.

Figure 4 gives temperature evolution during laser welding at different positions $(x=0.0, y=3.0 \mathrm{~mm})$, $(x=0.0, y=3.5 \mathrm{~mm})$, and $(x=0.0, y=4.0 \mathrm{~mm})$ on the weld bead for $P=2500 \mathrm{~W}$ of and $V=0.060 \mathrm{~m} / \mathrm{s}$. The same shape can be observed as other curves in the literature $[11,22]$. It is known that when there is convection heat transfer, the temperature profile approaches slightly to ambient temperature. This trend can be clearly observed in Figs. 3, 4.

The variation of the temperature is presented in Fig. 5 as a function of the position $x$ during welding for $P=2500 \mathrm{~W}$ and $V=0.060 \mathrm{~m} / \mathrm{s}$ at $t=0.1 \mathrm{~s}$. This figure shows that during laser welding there is an important thermal gradient near $x=0$. The temperature may vary between $400 \mathrm{~K}$ and $1500 \mathrm{~K}$ at a distance less than $0.4 \mathrm{~mm}$ from the weld bead, to note that $R=0.30 \mathrm{~mm}$.

Temperatures values were calculated on the weld bead at the point $(x=0 \mathrm{~mm}, y=2.5 \mathrm{~mm})$ for $P=2500 \mathrm{~W}$ and

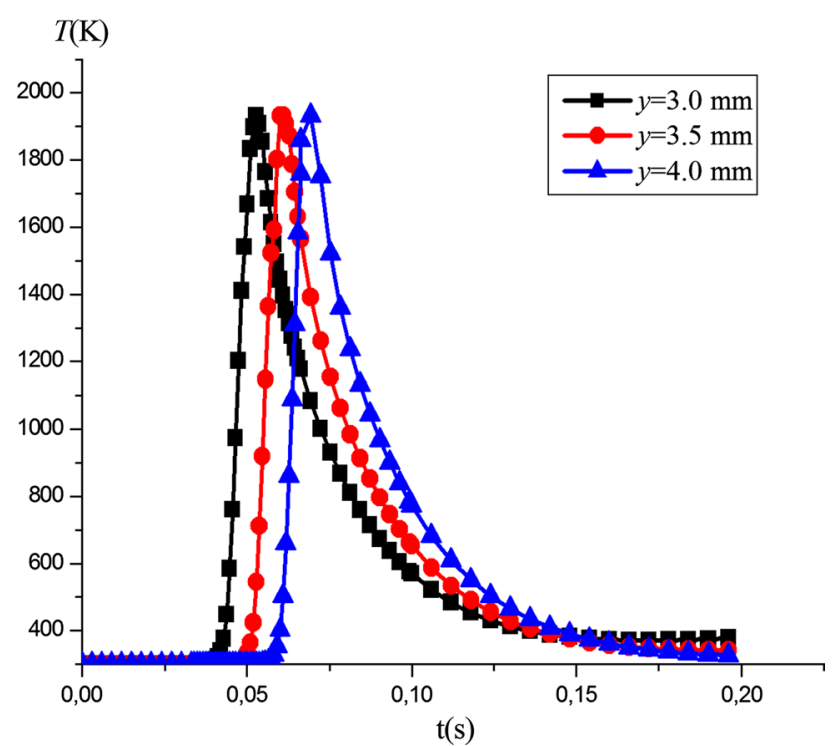

Fig. 4 Temperature evolution during laser welding at different positions on the weld bead $(P=2500 \mathrm{~W}, V=0.060 \mathrm{~m} / \mathrm{s})$

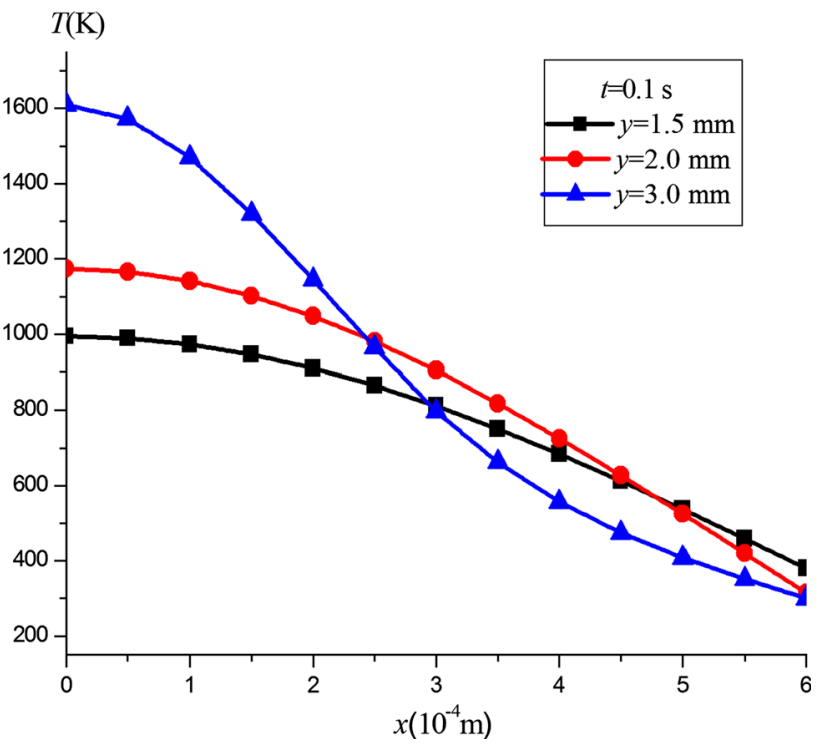

Fig. 5 Variation of the temperature as a function of the position $\mathrm{x}$ $(P=2500 \mathrm{~W}, V=0.060 \mathrm{~m} / \mathrm{s}, t=0.1 \mathrm{~s})$

Table 3 Variations of temperature with and without lost energy

\begin{tabular}{lccc}
\hline$t(\mathrm{~s})$ & $\begin{array}{l}T(\mathrm{~K}) \\
(\sigma=0, h=0)\end{array}$ & $\begin{array}{l}T_{\text {loss }}(\mathrm{K}) \\
(\sigma \neq 0, h \neq 0)\end{array}$ & $\Delta T / T_{\text {loss }}\left(10^{-2} \%\right)$ \\
\hline 0 & 300 & 300 & 0.0 \\
0.05 & 1542.840 & 1542.808 & 0.2074 \\
0.10 & 524.6337 & 524.5176 & 2.2135 \\
0.20 & 455.2927 & 454.6050 & 15.1274 \\
\hline
\end{tabular}

$V=0.040 \mathrm{~m} / \mathrm{s}$ with and without losses. The results are reported in Table 3. We can note that the variations of temperature $\Delta T / T$ do not exceed $0.2 \%$ after $0.20 \mathrm{~s}$.

Figures 6,7 show the energy lost by radiation and convection as function of time for $V=0.060 \mathrm{~m} / \mathrm{s}$ and $P=2500 \mathrm{~W}$. It can be seen that during welding, the energy lost by radiation or convection varies according to time and it is greater near the weld bead. The maximum value of energy lost by radiation (about $2.52 \times 10^{-4} \mathrm{~J}$ ) is greater than the maximum value of energy lost by convection (about $1.67 \times 10^{-4} \mathrm{~J}$ ). The energy lost by radiation is less than to the energy lost by convection in a duration time. We can see also that the energy lost by radiation is less than to the energy lost by convection in space function. So there is a competition between the two phenomena radiation and convection. As the laser beam radius $R=0.3 \mathrm{~mm}$, these two last conclusions confirm the hypothesis taken by Belhadj et al. [13], where they assumed the loss by radiation is on the irradiated surface by laser beam. These results confirm our choice for the form of power density $\left(Q(2 R, t)=\exp (-4) Q_{0}=0.02 Q_{0}\right)$, outside $2 R$ the energy lost by convection and radiation are negligible. 


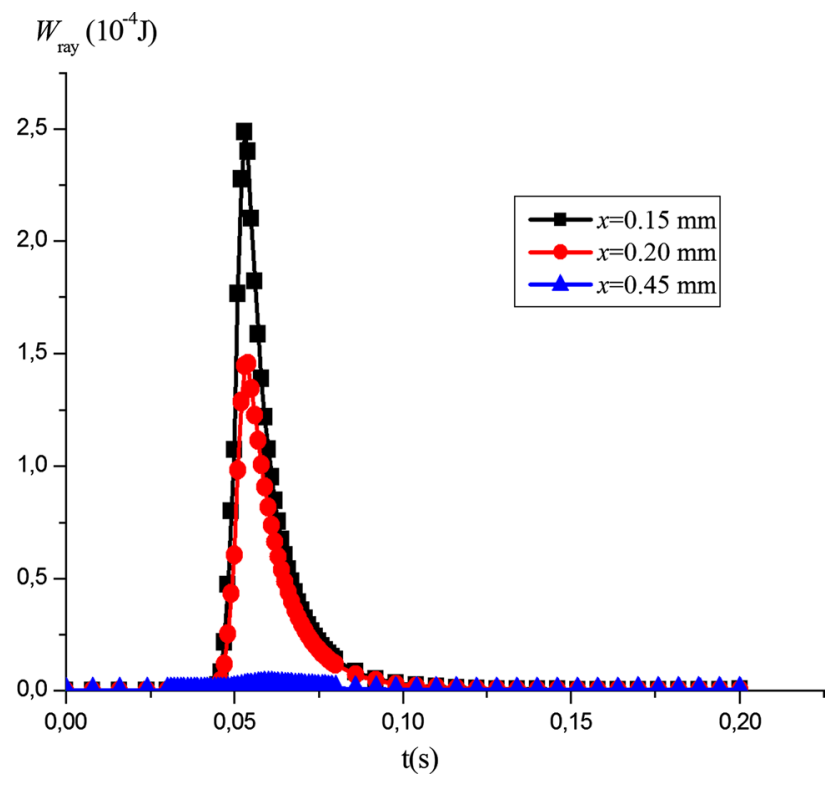

Fig. 6 Energy lost by radiation as a function of time at different positions $x$

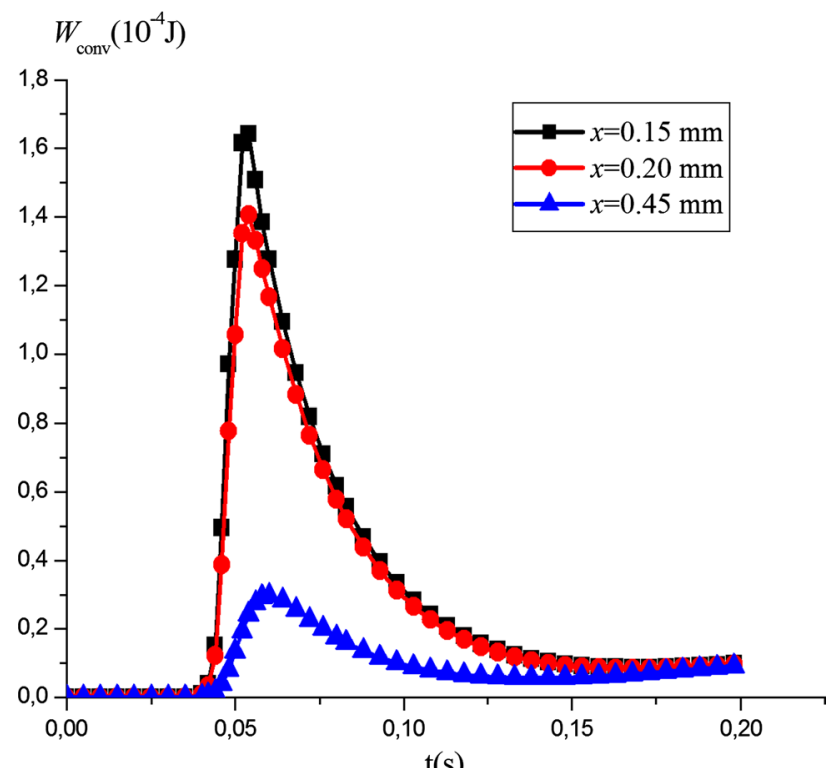

$t(s)$

Fig. 7 Energy lost by convection as a function of time at different positions $x$

For $R=0.30 \mathrm{~mm}, P=2500 \mathrm{~W}$ and $V=0.060 \mathrm{~m} / \mathrm{s}$, the energy lost from one plate at different zones during welding $(0.1 \mathrm{~s})$ is shown in Table 4 . Results show the loss in and near the weld bead is important per unit area, but the total energy lost, especially by convection, is most important on all the surface of the plate.

Energy lost at $y=2.0 \mathrm{~mm}$ as a function of position $x$ for different laser powers is illustrated in Fig. 8. We notice that along $x$ losses decrease. At every time, it can be observed that the lost energy was increased by increasing the laser power.

It is clear that the energy lost near and on the weld bead is greater than the energy lost in the rest of the plate. The temperatures can reach the $\beta$-transus temperature on the weld bead and near the weld bead. The exact calculation of the temperatures in those positions is required. Therefore, it is necessary to take into account energy losses on the weld bead and near the weld bead. The study of the influence of the results on the structure of the materials would require a more computation on the volume of the materials.

The amount of energy lost by convection and radiation for both plates of TA6V represented $2.5 \%$ of the energy balance during $0.10 \mathrm{~s}$ and $7 \%$ during $0.20 \mathrm{~s}$. In a previous work [14], both thermal convection and radiation in the welding area of magnesium alloy have been estimated to be about $20 \%$ of the laser power. This difference is probably due to several parameters such as physical properties, welding parameters, cooling rate, or calculation models.

\section{Conclusion and perspectives}

A numerical model has been used to determine temperature distribution as a function of welding time and position during the laser welding of two identical thin plates of TA6V. The amount of energy lost by radiation and convection could be calculated at any instant during welding. According to the results, the main conclusions are summarized as follows:

- The temperature evolutions produced by different welding velocities showed similar trends.

- The peak welding temperature was increased by decreasing the welding velocity.

- The numerical results obtained using the appropriate welding conditions were in good agreement with previous published experimental data.

- The energy loss depended on the position and power and the welding velocity and time.
Table 4 Lost energy during welding from one plate

\begin{tabular}{lllc}
\hline Zones & In the weld bead & Near the weld bead & In the rest of the plate \\
\hline Surface $\left(\mathrm{mm}^{2}\right)$ & 1.5 & 1.5 & 297.0 \\
$W_{\text {ray }}+W_{\text {conv }}\left(10^{-2} \mathrm{~J}\right)$ & 4.8792 & 4.8507 & 840.4866 \\
Loss per unit area $\left(\mathrm{J} / \mathrm{mm}^{2}\right)$ & 0.0325 & 0.0323 & 0.0283 \\
\hline
\end{tabular}




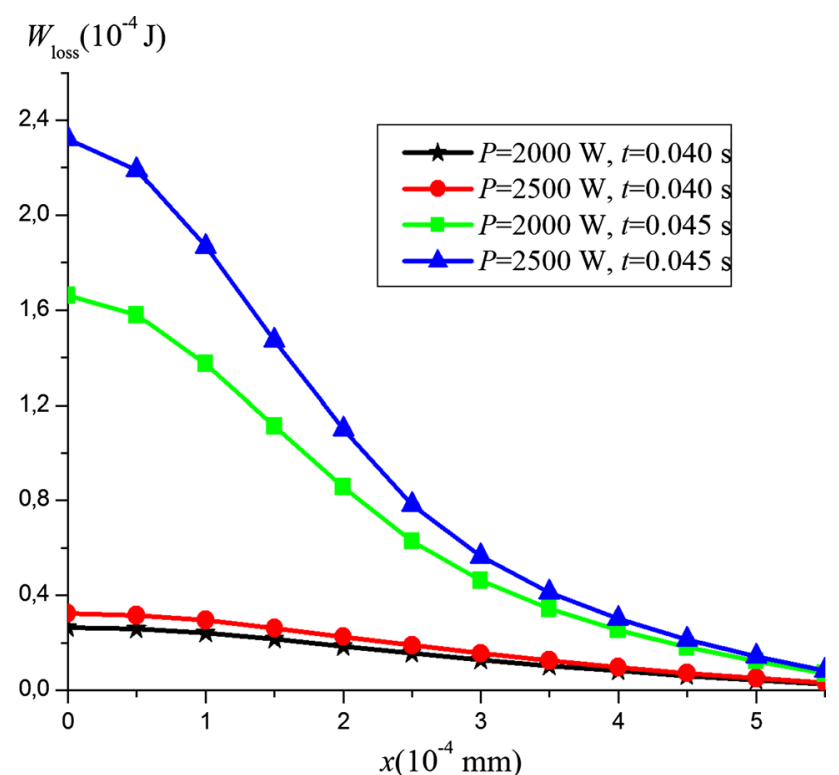

Fig. 8 Energy lost as a function of positions $x$ for different laser powers

- Under the welding conditions used in this study, variations in temperature $\Delta T / T$ did not exceed $0.2 \%$ after $0.20 \mathrm{~s}$, and the amount of energy lost by convection and radiation represented $7 \%$ of the energy balance.

- It is necessary to take into account energy losses in the welding area to improve laser welding efficiency.

As a perspective, it would be interesting to study metal vaporization and its impact on the welding area. Further, it would be interesting to study exactly how lost energy affects material structures. These last need a calculation in the volume of materials, in and near the weld bead, with an appropriate formulation of the laser power.

Open Access This article is distributed under the terms of the Creative Commons Attribution 4.0 International License (http://creative commons.org/licenses/by/4.0/), which permits unrestricted use, distribution, and reproduction in any medium, provided you give appropriate credit to the original author(s) and the source, provide a link to the Creative Commons license, and indicate if changes were made.

\section{References}

1. Kabir, A.S.H., Cao, X., Medraj, M., Wanjara, P., Cuddy J., Birur, A.: Effect of welding speed and defocusing distance on the quality of laser welded Ti-6Al-4V. In: Conference Proceeding Materials Science and Technology, MS\&T, Houston, Texas, pp. 2787-2797 (2010)

2. Yang, J., Sun, S., Brandt, M., Yan, W.: Experimental investigation and 3D finite element prediction of the heat affected zone during laser assisted machining of Ti6Al4V alloy. J. Mater. Process. Technol. 210, 2215-2222 (2010). https://doi.org/10. 1016/j.jmatprotec.2010.08.007
3. Boivineau, M., Cagran, C., Doytier, D., Eyraud, V., Nadal, M.H., Wilthan, B., Pottlacher, G.: Thermophysical properties of solid and liquid Ti-6Al-4V (TA6V) alloy. Int. J. Thermophys. 27(2), 507-529 (2006). https://doi.org/10.1007/s10765-005-0001-6

4. Niinomi, M.: Biologically and mechanically biocompatible titanium alloys. Mater. Trans. 49(10), 2170-2178 (2008). https://doi. org/10.2320/matertrans.L-MRA2008828

5. Elias, C.N., Lima, J.H.C., Valiev, R., Meyers, M.A.: Biomedical applications of titanium and its alloys. JOM 60(3), 46-49 (2008). https://doi.org/10.1007/s11837-008-0031-1

6. Auwal, S.T., Ramesh, S., Yusof, F., Manladan, S.M.: A review on laser beam welding of titanium alloys. Int. J. Adv. Manuf. Technol. (2018). https://doi.org/10.1007/s00170-018-2030-x

7. Mackwood, A.P., Crafer, R.C.: Thermal modelling of laser welding and related processes: a literature review. Opt. Laser Technol. 37, 99-115 (2005). https://doi.org/10.1016/j.optlastec. 2004.02.07

8. Davis, M., Kapadia, P., Dowden, J.: Modeling the fluid flow in laser beam welding. Suppl Weld J. pp. 147-167 (1986). http:// files.aws.org/wj/supplement/WJ_1986_07_s167.pdf. Accessed 25 Sept 2017

9. Abderrazak, K., Bannour, S., Mhiri, H., Lepalec, G., Autric, M.: Numerical and experimental study of molten pool formation during continuous laser welding of AZ91 magnesium alloy. Comput. Mater. Sci. 44, 858-866 (2009). https://doi.org/10.1016/ j.commatsci.2008.06.002

10. Bannour, S., Abderrazak, K., Mhiri, H., Le Palec, G.: Effects of temperature-dependent material properties and shielding gas on molten pool formation during continuous laser welding of AZ91 magnesium alloy. Opt. Laser Technol. 44, 2459-2468 (2012). https://doi.org/10.1016/j.optlastec.2012.03.034

11. Tirand, G., Arvieu, C., Lacoste, E., Quenisset, J.M.: Control of aluminum laser welding conditions with the help of numerical modeling. J. Mater. Process. Technol. 213, 337-348 (2013). https://doi.org/10.1016/j.jmatprotec.2012.10.014

12. Rai, R., Elmer, J.W., Palmer, T.A., DebRoy, T.: Heat transfer and fluid flow during keyhole mode laser welding of tantalum, Ti6Al-4V, 304L stainless steel and vanadium. J. Phys. D Appl. Phys. 40, 5753-5766 (2007). https://doi.org/10.1088/0022-3727/ 40/18/037

13. Belhadj, A., Bessrour, J., Masse, J.E., Bouhafs, M., Barrallier, L.: Finite element simulation of magnesium alloys laser beam welding. J. Mater. Process. Technol. 210, 1131-1137 (2010). https://doi.org/10.1016/j.jmatprotec.2010.02.023

14. Abderrazak, K., Ben Salem, W., Mhiri, H., Lepalec, G., Autric, M.: Modelling of $\mathrm{CO}_{2}$ laser welding of magnesium alloys. Opt. Laser Technol. 40, 581-588 (2008). https://doi.org/10.1016/j. optlastec.2007.10.003

15. Abderrazak, K., Kriaa, W., BenSalem, W., Mhiri, H., Lepalec, G., Autric, M.: Numerical and experimental studies of molten pool formation during an interaction of a pulse laser (Nd:YAG) with a magnesium alloy. Opt. Laser Technol. 41, 470-480 (2009). https://doi.org/10.1016/j.optlastec.2008.07.012

16. Fan, H.G., Tsai, H.L., Na, S.J.: Heat transfer and fluid flow in a partially or fully penetrated weld pool in gas tungsten arc welding. Int. J. Heat Mass Transf. 44, 417-428 (2001)

17. Negi, V., Chattopadhyaya, S.: Critical assessment of temperature distribution in submerged arc welding process. Adv. Mater. Sci. Eng. 2013, 1-9 (2013). https://doi.org/10.1155/2013/543594

18. Lemkeddem, S., Khemgani, S., Khelfaoui, F.: Radiation and convection losses during laser welding of TA6V titanium alloy. In: The 3rd International Seminar on Plasma Physics, Ouargla, Algeria, pp. 16-17 (2015)

19. Wanhill, R., Barter, S.: Fatigue of Beta Processed and Beta Heattreated Titanium Alloys. Springer, Dordrecht (2011). https://link. 
springer.com/book/10.1007\%2F978-94-007-2524-9. Accessed 25 Sept 2017

20. Ahn, J., Chen, L.: Davies. C. M., Dear, J. P.: Parametric optimization and microstructural analysis on high power Yb-fibre laser welding of Ti-6Al-4V. Opt. Laser Eng. 86, 156-171 (2016). https://doi.org/10.1016/j.optlaseng.2016.06.002

21. Mills, K.C.: Recommended Values of Thermophysical Properties for Selected Commercial Alloys, vol. 1, pp. 209-216. Antony Rowe Ltd, Wiltshire (2002)

22. Akbari, M., Saedodin, S., Toghraie, T., Shoja-Razavi, R., Kowsari, F.: Experimental and numerical investigation of temperature distribution and melt pool geometry during pulsed laser welding of Ti6Al4V alloy. Opt. Laser Technol. 59, 52-59 (2014)

23. Kabir, A.S.H., Cao, X., Gholipour, J., Wanjara, P., Cuddy, J., Birur, A., Medraj, M.: Effect of postweld heat treatment on microstructure, hardness, and tensile properties of laser-welded Ti-6Al-4V. Metall. Mater. Trans. A 43, 4148-4171 (2012)

24. Caiazzo, F., Curcio, F., Daurelio, G., Memola Capece Minutolo, F., Ottonelli, F.: Lap and butt joining by a $\mathrm{CO}_{2}$ laser of titanium alloys for civil and military high speed aircraft. In: 10th World Conference on Titanium, Hamburg, IV, pp. 2651-2658 (2003). https://www.researchgate.net/publication/236334788. Accessed 25 Sept 2017

Publisher's Note Springer Nature remains neutral with regard to jurisdictional claims in published maps and institutional affiliations. 